\title{
FORMULATION AND CHARACTERIZATION OF FLOATING TABLET DOSAGE FORM OF DUAL DELIVERY OF DRUG CURCUMIN AND BERBERINE HYDROCHLORIDE USING SIMULTANEOUS ESTIMATION BY UV SPECTROSCOPY
}

\section{KOLLOL KUMAR MAJUMDER ${ }^{1}$, MANISH KUMAR ${ }^{*}$, RAKESH PAHWA ${ }^{2}$, AVNEET KAUR LAMBA ${ }^{3}$, RAVI SHANKAR ${ }^{4}$, ABHISHEK TIWARI ${ }^{5}$, VARSHA TIWARI ${ }^{5}$, RISHABH ${ }^{1}$}

\begin{abstract}
1M. M. College of Pharmacy, Maharishi Markandeshwar (Deemed to be University), Mullana-Ambala, Haryana 133207, ${ }^{2}$ Institute of Pharmaceutical Sciences, Kurukshetra University, Kurukshetra 136119, Haryana, India, ${ }^{3}$ Department of Pharmaceutical Sciences, Gurugram University, Gurugram 122003, 4Department of Pharmacy, Sagar Institute of Technology and Management, Barabanki, Uttar Pradesh, 225001, ${ }^{5}$ Department of Pharmacy, Devsthali Vidyapeeth College of Pharmacy, Lalpur, Rudrapur (U. S. Nagar), Uttrakhand, India Email: manish_singh17@rediffmail.com
\end{abstract}

Received: 18 May 2021, Revised and Accepted: 05 Jun 2021

ABSTRACT

Objective: The present study was aimed to develop a combinational floating tablet of curcumin and berberine HCl utilizing synthetic polymers synthetic HPMC K-15M and evaluate its various characteristics.

Methods: The formulations were developed by the process of wet granulation and evaluated for drug content, content uniformity, floating lag time, total floating time, in vitro buoyancy studies, and in vitro drug release profile. A simultaneous estimation method for curcumin and berberine was developed using U. V spectroscopy.

Results: The results clearly indicated that the tablets produced were having acceptable physical parameters. The absence of any drug/polymer/excipient interactions was confirmed using infrared spectroscopy. It was found that the drug content of was in between 96.22 to $99.45 \%$ in all the formulations. Because of their low densities, in vitro floatability tests showed that most of the tablets floated for more than $8 \mathrm{~h}$. The in vitro release studies confirmed the sustained release of more than 80 percent of drug contained within a period of $8 \mathrm{~h}$. In vitro buoyancy was good in all three batches (F1-F3). The overall floating time for the F2 formulation was $24 \mathrm{~h}$. After one month of storage at $40{ }^{\circ} \mathrm{C}$ and 75 percent $\mathrm{RH}$, the F2 formulation showed no noticeable change in physical as well as pharmaceutical performance characteristics.

Conclusion: Floating tablets of curcumin and berberine was successfully developed and had passed on various pharmaceutical parameters.

Keywords: Curcumin, Berberine hydrochloride, HPMC K-100M, HPMC K-15M, Floating, Sodium bi carbonate, In Vitro Buoyancy

(C) 2021 The Authors. Published by Innovare Academic Sciences Pvt Ltd. This is an open access article under the CC BY license (https://creativecommons.org/licenses/by/4.0/)

DOI: https://dx.doi.org/10.22159/ijap.2021v13i5.42098. Journal homepage: https://innovareacademics.in/journals/index.php/ijap

\section{INTRODUCTION}

Curcumin has been termed as a golden drug molecule as it find its therapeutic application for various disease indications and serves as i.e., antioxidant, anti-inflammatory, anti-infective, anti-Alzheimer, anti-tumor, anti-diabetic, and anti-rheumatic agent $[1,2]$. It has also been shown to be a hypoglycemic, hepatoprotective, nephroprotective, cardio-protective, and neuroprotective moiety [3]. It has also been reported to prevent myocardial infarction and suppresses thrombosis. It is the most popular polyphenol, very commonly consumed daily with food (in India, SAARC countries), which contributes to better compliance.

Berberine is a naturally occurring compound obtained from the bark, stem and roots of a number of clinically valuable medicinal plants, including Hydrastis Canadensis (goldenseal), Berberis Aristata (true turmeric), and Berberis vulgaris (barberry), Berberis Aquifolium (Oregone grape), It also possess activity against diabetes, hypertension, arrhythmia and serve also as anti-tumor, anti-fungal, anti-oxidative, anti-inflammatory, cerebro-protective agent $[4,5]$

Curcumin and berberine both natural compounds are quite stable in acidic $\mathrm{pH}$ but have limited solubility requiring extra bit of time in stomach for complete dissolution and absorption leading to maximum bioavailability. Gastroretentive dosage forms (GRDFs) are a drug delivery formulation that is designed to remain in the gastric region for a long period and significantly prolong the gastric retention time (GRT) of drugs. A floating dosage unit is valuable drug delivery systems for drugs that act locally in the distal part of the stomach or proximal part of the intestine. It is also a good option for candidates, which are poorly soluble or unstable in intestinal fluids $[6,7]$. So, we aimed at developing a floating drug delivery system for delivering curcumin and berberine simultaneously and also development of analytical UV spectroscopic method for simultaneous determination of both drugs.

\section{MATERIALS AND METHODS}

Drugs and reagents

The gift sample of Curcumin and Berberine hydrochloride was received from Alexi Pharmica, Baddi, Solan, and Himachal Pradesh, India. Analytical grade solvents were obtained from Rankem (Mumbai, India)

\section{Equipments}

These instruments double beam (Electronic India 2375, HP, India) UV visible spectrophotometer, (Shimadzu ELB 300) electrical balance and (PCI analytics Pvt. Ltd) ultrasonic bath and dissolution tester (model EDT-08 Lx) which contain eight station was used for the purpose of simultaneous estimation.

\section{Simultaneous estimation using UV method}

From stock- I solutions of both drugs of curcumin and berberine $\mathrm{HCl}$ were prepared in solution. Further dilution of the stock solutions was concentration range at $2-12 \mu \mathrm{g} / \mathrm{ml}$ of both drugs. The wavelength of maximum absorbance and absorptivity of both drugs to determined by the double beam UV spectrophotometer. The absorbance maxima of curcumin are $349 \mathrm{~nm}$ and berberine $\mathrm{HCl}$ are $420 \mathrm{~nm}$. The absorptivity values of curcumin are $\left(\mathrm{ax}_{1}\right) 0.030$ at $420 \mathrm{~nm}$ and $\left(\mathrm{ax}_{2}\right) 0.027$ at 349 $\mathrm{nm}$. And the absorptivity values of berberine $\mathrm{HCl}$ are (ay) 0.215 at $349 \mathrm{~nm}$ and $\left(\mathrm{ay}_{2}\right) 0.039$ at $420 \mathrm{~nm}$. The absorptivity values of both drugs replaced in following equation:

$$
\frac{C x=\text { A2ay } 1-\text { A1ay2 }}{\text { ax2ay1-ax1ay2 }}
$$




$$
C y=\frac{\mathrm{A} 1 \mathrm{ax} 2-\mathrm{A} 2 \mathrm{ax} 1}{\mathrm{ax} 2 \mathrm{ay} 1-\mathrm{ax} 1 \mathrm{ay} 2}
$$

Here, $A_{1}$ and $A_{2}$ are absorbance of combination tablet formulation of two drugs at $420 \mathrm{~nm}$ and $349 \mathrm{~nm}$ of both drugs severally. At first ten tablets were accurately weighted and the average weight was determined. The equivalent weight of powder was withdrawn and was transfered to the $100 \mathrm{ml}$ volumetric flask which contain $50 \mathrm{mg}$ curcumin and $50 \mathrm{mg}$ berberine hydrochloride. The powder dissolved the solvent and the further dilution of the solutions was prepared the working standard concentration $5 \mu \mathrm{g} / \mathrm{ml}$ of curcumin and 5 $\mu \mathrm{g} / \mathrm{ml}$ of berberine hydrochloride $[8,9]$.

\section{Analytical method validation}

Validation is widely described as (ICH) establishing documented proof that a chosen operation can systematically produce a desired outcome or product that meets its predetermined requirements and quality characteristics. The objective of method validation is to confirm that the above said method will give reproducible and reliable results that could be utilized and are adequate for the required purpose. The process was validated using a variety of parameters, including linearity and range, specificity, precision, accuracy, and ruggedness, as well as LOQ and LOD.

\section{Preparation of floating tablet by direct compression method (F1-F3)}

Direct compression was used to render the floating tablets. Curcumin, berberine hydrochloride, and HPMC K15M were all weighed separately and passed through sieve No. 10 to obtain uniform size particles for efficient and homogeneous mixing. The powders were homogeneously mixed for half an hour. As a lubricant and anti-adhesive, talc and magnesium stearate were also combined in a fixed volume. The homogeneous blend prepared was finally compresses using tablet punching machine (table 1).

Table 1: Formulation table for floating tablets by wet granulation method

\begin{tabular}{llll}
\hline S. No. & Ingredients & F1 & F2 \\
\cline { 3 - 4 } & & Quantity (mg) & \\
\hline 1 & Curcumin & 50 & 50 \\
2 & Berberine HCl & 50 & 50 \\
3 & HPMCK15M & 40 & 60 \\
4 & Sodium bicarbonate & 20 & 20 \\
5 & Gum & 15 & 15 \\
6 & Citric acid & 15 & 15 \\
7 & Ethyl cellulose & 10 & 15 \\
8 & Aerosil & 2.5 & 15 \\
9 & Magnesium stearate & 2.5 & 15 \\
\end{tabular}

\section{Evaluation of floating tablets}

Tablet thickness, stiffness, friability test, drug quality, and content uniformity were among the pharmaceutical parameters evaluated according to official compendia $[10,11]$.

\section{Weight variation}

A digital weighing balance was used to measure 20 tablets from formulation F1, F2 and F3 respectively, and the average weight was determined individually of the three different batches. The average weight was compared with the individual weight of all tablets of that particular batch [12].

\section{Hardness}

The Monsanto hardness tester was utilized determine the hardness of the tablets. Ten tablets were taken and hardness was determined. The average value was calculated each of the batches [13].

\section{Friability test}

The percent friability was calculated using an Electrolab friabilator (USP). Ten tablets were accurately weighted before being placed in an Electrolab friabilator and rotated at $25 \mathrm{rpm}$ for four minutes $(100$ revolutions) [12].

\section{Drug content}

The substance was dissolved in methanol and filtered through a 0.45 membrane after ten tablets were weighed individually. Using a double beam spectrophotometer UV 2375 electronics India, the absorbance was measured at $420 \mathrm{~nm}$ and $349 \mathrm{~nm}$ after sufficient dilution [12].

\section{Content uniformity}

Ten tablets were chosen at random and individually weighed and powdered. $50 \mathrm{mg}$ of tablet powder was taken and was dissolved in $100 \mathrm{ml}$ methanol. The solution was prepared followed by sonication for $15 \mathrm{~min}$. The un-dissolved matter was filtered out. The absorbance of the diluted solutions was calculated at $420 \mathrm{~nm}$ and $349 \mathrm{~nm}$ respectively [13].

\section{Floating lag time (FLT)}

Floating lag time was measured as the time it took for the tablet to rise to the surface and float. The tablet was kept in a $200 \mathrm{ml} 0.1 \mathrm{~N} \mathrm{HCL}$ solution (pH 1.2) at $37^{\circ} \mathrm{C}$ contained in a $250 \mathrm{ml}$ glass beaker [14].

\section{Total floating time}

The cumulative floating time was measured as the amount of time the dosage formulation stayed continuously on the medium's surface. The tablet was kept in a $200 \mathrm{ml} 0.1 \mathrm{~N} \mathrm{HCL}$ solution (pH 1.2) at $37^{\circ} \mathrm{C}$ contained in a $250 \mathrm{ml}$ glass beaker. The total floating time was observed [15].

\section{Swelling index}

The ability of the polymer to swell and related floating time mainly depends on the contents of the stomach and the osmolarity of the medium. These ultimately have an effect on the release, delaying the action and extending the residence time. The individual tablets were weighed and were put in a beaker containing $200 \mathrm{ml}$ of $0.1 \mathrm{~N} \mathrm{HCL}$. The tablet from the beaker was removed and was weighed every hour and the process was continued till constant weight was observed for subsequent three readings. The percent weight gain was calculated utilizing the formula [16].

$$
S . I .=\frac{(\mathrm{Wt}-\mathrm{W0}) \times 100}{\mathrm{~W} 0}
$$

$\mathrm{W}_{0}=$ is the initial weight of tablet, $\mathrm{W}_{\mathrm{t}}=$ is the weight of the tablet at time $\mathrm{t}$.

\section{In vitro dissolution studies}

O-Electro-lab dissolution apparatus was utilized with $900 \mathrm{ml} 0.1 \mathrm{~N}$ HCL (pH1.2) solution at body temperature using USP paddle apparatus at $50 \mathrm{rpm}$ for carrying out in vitro drug release studies of formulations. An aliquot of $5 \mathrm{ml}$ is extracted from the solution and a fresh aliquot of $5 \mathrm{ml}$ was added to it. The samples were taken at a fixed interval of time for up to $8 \mathrm{~h}$. The sample was filtered, and $3 \mathrm{ml}$ was taken from the filtrate. The absorbance of the solution was determined by using UV spectrophotometer at $420 \mathrm{~nm}$ and $349 \mathrm{~nm}$ and further the amount of drug release was calculated [17]. 


\section{Release kinetics}

The kinetics of drug release was studied using a variety of models. The obtained data were fitted into zero-order, first order, Higuchi model, and korsemeyer Peppas release models to evaluate and characterize the release mechanism of drug and drug release kinetics of the dosage type [18].

\section{RESULTS AND DISCUSSION}

\section{Simultaneous estimation using UV method}

From stock- I solutions of both drugs of curcumin and berberine, $\mathrm{HCl}$ was prepared in solution. Further dilution of the stock solutions was a concentration range at $2-12 \mu \mathrm{g} / \mathrm{ml}$ of both drugs. The wavelength of maximum absorbance and absorptivity of both drugs to be determined by the double beam UV spectrophotometer. The absorbance maxima of curcumin are $420 \mathrm{~nm}$ and berberine $\mathrm{HCl}$ are $349 \mathrm{~nm}$ (table 2).

\section{Post compression parameters}

The detailed results of weight variation, thickness, hardness, friability is mentioned in table 3. It was found the values were within the specified acceptable limit.

\section{Swelling index}

Water intake ratio or swelling index of formulations F1-F3 is given in table 3 . The results clearly indicate that all three formulations have good swelling capability and the swelling index is linearly related to the concentration of the polymer used [19].

Table 2: Observation data of simultaneous method of both drugs

\begin{tabular}{|c|c|c|c|c|c|c|c|}
\hline & \multirow{2}{*}{$\begin{array}{l}\text { Pure drug } \\
(\mu \mathrm{g} / \mathrm{ml})\end{array}$} & \multicolumn{2}{|c|}{ Absorbance } & \multicolumn{2}{|c|}{ Absorptivity } & \multirow{2}{*}{$\begin{array}{l}\text { Theoretical } \\
\text { concentration }(\mu \mathrm{g} / \mathrm{ml})\end{array}$} & \multirow{2}{*}{$\begin{array}{l}\text { Experimental } \\
\text { concentration }(\mu \mathrm{g} / \mathrm{ml})\end{array}$} \\
\hline & & $349 \mathrm{~nm}$ & $421 \mathrm{~nm}$ & Ax1 & Ax2 & & \\
\hline \multirow[t]{5}{*}{ Curcumin } & 2 & 0.007 & 0.006 & 0.0035 & 0.003 & \multirow[t]{5}{*}{$5 \mu \mathrm{g} / \mathrm{ml}$} & \multirow[t]{5}{*}{$4.55 \mu \mathrm{g} / \mathrm{ml}$} \\
\hline & 4 & 0.009 & 0.011 & 0.0022 & 0.0027 & & \\
\hline & 6 & 0.019 & 0.016 & 0.0031 & 0.00266 & & \\
\hline & 8 & 0.027 & 0.021 & 0.0033 & 0.00262 & & \\
\hline & 10 & 0.029 & 0.026 & 0.0029 & 0.0026 & & \\
\hline Berberine & & $349 \mathrm{~nm}$ & $420 \mathrm{~nm}$ & Ay1 & Ay2 & \multirow{6}{*}{$5 \mu \mathrm{g} / \mathrm{ml}$} & \multirow{6}{*}{$2.04 \mu \mathrm{g} / \mathrm{ml}$} \\
\hline \multirow[t]{5}{*}{ hydrochloride } & 2 & 0.041 & 0.007 & 0.0205 & 0.0035 & & \\
\hline & 4 & 0.079 & 0.011 & 0.019 & 0.00275 & & \\
\hline & 6 & 0.117 & 0.021 & 0.0195 & 0.0035 & & \\
\hline & 8 & 0.189 & 0.038 & 0.0236 & 0.0047 & & \\
\hline & 10 & 0.243 & 0.052 & 0.0243 & 0.0052 & & \\
\hline
\end{tabular}

Table 3: Pharmaceutical parameters of formulations F1-F3

\begin{tabular}{llll}
\hline Formulation & Weight variation (mg) & Tablet thickness (mm) & Hardness (kg/cm $)$ \\
\hline F1 & $249 \pm 5$ & $4.04 \pm 05$ & $4.5 \mathrm{~kg} / \mathrm{cm}^{3}$ \\
F2 & $251 \pm 5$ & $4.11 \pm 05$ & $3.5 \mathrm{~kg} / \mathrm{cm}^{3}$ \\
F3 & $248 \pm 5$ & $4.00 \pm 05$ & $5.0 \mathrm{~kg} / \mathrm{cm}^{3}$ \\
\hline
\end{tabular}

$($ mean $\pm \mathrm{SD}, \mathrm{n}=3$ )

\section{Floating lag time and total floating time}

All the formulations have floating time within $30 \mathrm{sec}$ to $12 \mathrm{~min}$ range. F1 formulation shows a minimum floating time $60 \mathrm{sec}$. floating lag time is depending on the amount of gas generating agents. Sometimes the amount of polymer also effects the floating lag time as the amount of polymers increased the floating lag time also increased but it was also found that the total floating time (TFT) also increased. The detailed data of floating lag time and (TFT) is mentioned in table 4. Total floating time depends on the amount of hydrophilic polymer in the formulation. The higher the amount it will remains float longer period of time. F2 batch float up to $10 \mathrm{hr}$ while formulation $\mathrm{F} 3$ floated for more than $12 \mathrm{~h}$ which was desired for the sustained release dosage form [18].

Table 4: Pharmaceutical parameters of formulations F1-F3

\begin{tabular}{llllll}
\hline Formulation & Drug content (\%) & Content uniformity (\%) & Swelling index (\%) & Floating lag time (sec) & Total floating time (h) \\
\hline F1 & 94.20 and $93.18 \%$ & 97.05 and $92.70 \%$ & $30.6 \pm 2.3$ & $60 \pm 3$ & 8 \\
F2 & 96.90 and $92.24 \%$ & 97.98 and $92.12 \%$ & $36 \pm 1.56$ & $240 \pm 4$ & 10 \\
F3 & 95.78 and 91.29\% & 96.80 and 92.35\% & $48.5 \pm 3.2$ & $480 \pm 2$ & 12 \\
\hline
\end{tabular}

(mean \pm SD, $n=3$ )

Table 5: In vitro drug release data

\begin{tabular}{lllllll}
\hline $\begin{array}{l}\text { Time } \\
\text { (min) }\end{array}$ & $\begin{array}{l}\text { Percent release of } \\
\text { berberine (f1) }\end{array}$ & $\begin{array}{l}\text { Percent release of } \\
\text { curcumin (f1) }\end{array}$ & $\begin{array}{l}\text { Percent release of } \\
\text { berberine (f2) }\end{array}$ & $\begin{array}{l}\text { Percent release of } \\
\text { curcumin (f2) }\end{array}$ & $\begin{array}{l}\text { Percent release of } \\
\text { berberine (f3) }\end{array}$ & $\begin{array}{l}\text { Percent release of } \\
\text { curcumin (f3) }\end{array}$ \\
\hline 0 & 0 & 0 & 0 & 0 & 0 & 0 \\
15 & 14.88 & 17.65 & 12.07 & 14.61 & 17.21 & 17.04 \\
30 & 39.71 & 24.01 & 30.73 & 15.38 & 33.54 & 24.26 \\
60 & 51.69 & 34.13 & 39.65 & 24.65 & 46.04 & 32.82 \\
120 & 61.42 & 44.32 & 49.88 & 34.88 & 55.33 & 43.29 \\
180 & 64.31 & 64.17 & 56.09 & 46.13 & 63.03 & 53.72 \\
240 & 80.99 & 75.43 & 75.54 & 55.74 & 68.63 & 75.01 \\
300 & 87.48 & 85.80 & 80.65 & 76.36 & 78.64 & 85.38 \\
360 & 90.90 & 96.28 & & & 86.04 & \\
\hline
\end{tabular}




\section{In vitro drug release study}

The optimized dissolution condition was applied for in vitro dissolution of Curcumin and Berberine Hydrochloride tablets. It was found that the prepared floating tablets were capable of releasing the drug in a sustained way for $8 \mathrm{~h}$ and the rate of release of drug was inversely proportional to the polymer utilized thus sustaining effect is directly related to polymer concentration. It was found that the drug delivery system was able to release both the drugs simultaneously and at a slower pace (table 5) $[19,20]$.

\section{In vitro buoyancy studies}

The results confirmed that the floating tablets formulated were able to provide the required buoyancy ability. F1 formulation containing minimum concentration was found to have floating lag time less than 2 $\min$. The formulations started floating after a lag time and after that were buoyant for the study hours taken as detailed in table.

\section{Release kinetics}

The in vitro release data of formulations were treated with the different kinetic model to explain the release kinetics of Curcumin and berberine $\mathrm{HCl}$ from floating tablets. These models were zero order, first order, higuchi model and Korsemeyer Peppas model. Among them, Higuchi model was the best-fitted model (table 6 and table 7).

\section{Stability study}

The samples subjected to stability studies were analyzed. The result of the stability studies is detailed in table 8 . It was clearly revealed that the formulation was able to with-hold the required physical and pharmaceutical characteristics for the time period of the study. The drug content was more than 90 percent for the whole period and the content uniformity was also found to be more than 90 percent. The technical properties like swelling index and floating time also remained unchanged (table 8 ).

Table 6: Kinetics of curcumin release

\begin{tabular}{|c|c|c|c|c|c|}
\hline \multirow[t]{2}{*}{ Formulation } & Zero order & First order & Higuchi matrix & Korsmeyer peppas & \multirow[t]{2}{*}{ Best fit model } \\
\hline & $\mathbf{R}^{2}$ & $\mathbf{R}^{2}$ & $\mathbf{R}^{2}$ & $\mathbf{R}^{2}$ & \\
\hline F1 & 0.964 & 0.915 & 0.989 & 0.976 & Higuchi plot \\
\hline $\mathrm{F} 2$ & 0.977 & 0.982 & 0.980 & 0.989 & Korsmeyer peppas \\
\hline F3 & 0.954 & 0.968 & 0.992 & 0.982 & Higuchi plot \\
\hline
\end{tabular}

Table 7: Kinetics of berberine $\mathrm{HCl}$ release

\begin{tabular}{lllll}
\hline Formulation & Zero order & First order & Higuchi matrix & Korsmeyer peppas \\
\cline { 2 - 5 } & $\mathbf{R}^{\mathbf{2}}$ & $\mathbf{R}^{\mathbf{2}}$ & $\mathbf{R}^{\mathbf{2}}$ & $\mathbf{R}^{\mathbf{2}}$ \\
\hline F1 & 0.837 & 0.970 & 0.958 & 0.948 \\
F2 & 0.888 & 0.975 & 0.981 & 0.958 \\
F3 & 0.862 & 0.967 & 0.977 & 0.950 \\
\hline
\end{tabular}

Table 8: Results of stability study

\begin{tabular}{lllll}
\hline Formulation & Drug content (\%) & Swelling index (\%) & $\begin{array}{l}\text { Floating lag time } \\
\text { (sec) }\end{array}$ & $\begin{array}{l}\text { Total floating } \\
\text { time (h) }\end{array}$ \\
\hline F1 & $92.19 \pm 3.08$ and $91.87 \% \pm 3.96$ & 32.7 & $90 \pm 4$ & 9 \\
F2 & $95.09 \pm 4.52$ and $93.45 \% \pm 2.85$ & 26.3 & $300 \pm 5$ & 10 \\
F3 & $94.16 \pm 3.35$ and $96.88 \% \pm 4.89$ & 31.3 & $450 \pm 2$ & 94.04 and $91.70 \%$ \\
\hline
\end{tabular}

\section{CONCLUSION}

The results clearly revealed that the HPMC polymer-based tablets were able to achieve the floating time of more than $8 \mathrm{~h}$ and have the potential to enhance the bioavailability of drugs that are specifically absorbed from the stomach region by prolonging the residence tim with sustained release in the stomach. It was discovered that floating drug delivery tablets with polymers for sustained release and a gas-producing agent were able to prolong the residence time of curcumin and berberine in the upper part of GIT where the drug is stable and better absorbed achieving the overall goal of better therapeutic efficacy of the product.

\section{ACKNOWLEDGEMENT}

The authors are thankful to Alexi Pharmica, Baddi, Solan, and Himachal Pradesh, India for gift sample of pure drugs of Curcumin and Berberine hydrochloride and also thankful to the M. M. College of Pharmacy management for giving permission to used instruments and facilities of this project.

\section{FUNDING}

The authors declare that they have no funding support for this study.

\section{AUTHORS CONTRIBUTIONS}

All authors have contributed equally.

\section{CONFLICT OF INTERESTS}

The authors declare that they have no conflict of interest.

\section{REFERENCES}

1. Aggarwal BB, Sundaram C, Malani N, Ichikawa H. Curcumin: the Indian solid gold. Adv Exp Med Biol 2007;595:1-75.

2. Maheshwari RK, Singh AK, Gaddipati J, Srimal RC. Multiple biological activities of curcumin: a short review. Life Sci 2006;78;2081-7.

3. Trujillo J, Chirino YI, Molina Jijon E, Anderica Romero AC, Tapia E, Pedraza Chaverri J. Renoprotective effect of the antioxidant curcumin: recent findings. Redox Biol 2013;1:448-56.

4. Ji J, He X, Yang XL. The In vitro/vivo evaluation of prepared gastric floating tablets of berberine hydrochloride.AAPS PharmSciTech 2017;18:2149-56.

5. Patel M, Rathod IS, Sindhu BE. HPTLC method for estimation of berberine in ayurvedic formulations containing berberis aristata by an acid dye method. Int J Pharm Pharm Sci 2013;5:129-31.

6. Tekade BW, Jadhav UT, Patil SG, Patil VR. Formulation and in vitro evaluation of floating tablets of cefpodoxime proxetil. Int J Curr Pharm Res 2017;9:18-22.

7. Bhubaneswar S, Manikandan S, Akshay M, Nify F. Formulation and evaluation of gastroretentive micro balloons of Acebrophylline for the treatment of bronchial asthma. Asian J Pharm Clin Res 2016;9:105-11.

8. Sarojini SR, Manavalan R. A review on various approaches to gastroretentive dosage forms. Int J Drug Dev Res 2011;4:1-13.

9. Varsha BM, Surekha B, Nita K. Development of UVspectrophotometric method for the simultaneous estimation of simvastatin and ezetimibe in tablet dosage form by 
simultaneous equation and absorbance ratio method. Int J Pharm Tech Res 2011;3:1459-60.

10. Warule PS, Patel VP, Gosavi S. Development and validation of UV-spectrophotometric method for estimation of curcumin in an ayurvedic formulation haridrakhand. Int J Pharm Drug Anal 2017;5:193-7.

11. Mayavanshi AV, Gajjar SS. Floating drug delivery system to increase gastric retention of drugs: a review. Res J Pharm Tech 2008;1:345-8.

12. Saito N, Konishi K, Sato F, Kato M, Takeda H, Sugiyama T, et al. Plural transformation-processes from spiral to coccoid Helicobacter pylori and its viability. J Infect 2003;46:49-55.

13. Albadry AA, Ali WK, Saddy FA. Formulation and evaluation of prochlorperazine maleate sustained release floating tablet. Int J Pharm Pharm Sci 2017;9:89-98.

14. Emara LH, Abdou AR, Ashmawy AA, Mursi NM. Preparation and evaluation of metronidazole sustained release floating tablets. Int J Pharm Pharm Sci 2014;6:198-204.

15. Sandip B, Sapkal MB, Narkhede GD, Mehetre PV, Rane A, Pant $M$. Formulation and evaluation of gastro retentive floating tablet of Acyclovir. World J Pharm Sci 2012;1:1402-12.

16. Joushan A, Rabiul H, Puja B. Formulationandamp; in vitro evaluation of Gastroretentive floating drug delivery system of
Mebhydrolin napadisylate. World J Pharm Sci 2017;6:291305.

17. Prakash S. Formulation and evaluation of floating tablet of zolmitriptan tablet. Int J Adv Sci Technol 2019;28:825-41.

18. Ramji AKA, Chandra SRG, Prabhakar RV. Formulation, and evaluation of swellable and floating Gastroretentive ciprofloxacin hydrochloride tablets. AAPS Pharm Sci 2009;10:220-6.

19. Prabakaran B, Elango K, Ramesh K, Jaison KD. Formulation development and evaluation of gastroretentive bilayer floating tablets of simvastatin and telmisartan. Int J Pharm Res Rev 2016;5:9-18.

20. Rani PS, Neelima T, Jayanth RV, Lavanya R. Formulation and evaluation of HPMC and physillium husk based floating tablets of curcumin for ulcer. J Adv Pharm Edu Res 2014;4:720-82.

21. Klausner EA, Lavy E, Friedman M, Hoffman A. Expandable gastroretentive dosage forms. J Controlled Release 2003;90:143-62.

22. Rawat S, Shradha NS, Akhilesh G. Formulation and evaluation of floating matrix tablets of acyclovir using factorial design. Res J Pharm Dosage Form Tech 2018;10:1-9.

23. Sadhana S, Ashok S, Suhas V, Nityanand Z. Formulation and in vitro characterization of acyclovir floating matrix tablets: a factorial design study. J Appl Pharm Sci 2013;3:65-74. 